\title{
O LIVRO DA HOSPITALIDADE: ACOLHIDA DO ESTRANGEIRO NA HISTÓRIA E NAS CULTURAS
}

São Paulo, Editora SENAC, 2011, 1.437p.

Numa época de grande mobilidade humana e de multiplicação dos contatos interculturais, o tema da recepção e acolhida do diferente vem ganhando mais espaço, problematizando as formas estabilizadas de convivência, na interação entre os povos e no interior de uma mesma sociedade. Prova disso é o lançamento dessa obra enciclopédica pela Editora SENAC, cuja ambição é a de cobrir da maneira mais ampla possível um tema antigo, mas que cresce cada vez mais em importância: a hospitalidade. Nas palavras de seu próprio organizador, Alain Montandon, o que se procurava era produzir "um dicionário raciocinado da hospitalidade" (p.35), numa sequência de verbetes em ordem alfabética. Porém, viu-se a dificuldade em se realizar esse projeto com um tema como o da hospitalidade, que toca uma multiplicidade de campos do conhecimento humano, assim como de diferentes experiências existenciais. Pois, apesar dessa ambição totalizante, essa obra não deixa de possuir o seu viés metodológico, epistemológico e temático, que restringe de alguma maneira sua abordagem, excluindo temáticas tão importantes hoje como o turismo e a sua gestão. Essa observação é feita com bastante pertinência no prefácio à edição brasileira, por Luis Octavio de Lima Camargo, o qual, ao mesmo tempo que realça o valor dessa publicação, descreve, com várias indicações de diferentes autores, algumas linhas de estudo da chamada "hospitalidade comercial", sobretudo na "gestão do receptivo turístico" e na "recepção hoteleira" (p. 18-27). Enfim, esses campos de estudo da hospitalidade na prática da gestão comercial são os que melhor explicam que seja uma editora como a do Serviço Nacional do Comércio (SENAC) a que se tenha interessado pela publicação desta obra. 
Assim, os trabalhos reunidos nessa publicação possuem em comum uma exploração ampla no terreno da filosofia, da história, do estudo das religiões, da etnografia, da antropologia, das várias artes e das ciências políticas, pelos vários significados que vem assumindo a prática da hospitalidade, e suas principais temáticas correlatas. Nesse sentido, reflete uma linha de estudos caracteristicamente francesa, o que se percebe pela quase totalidade dos autores que contribuíram para a realização do projeto. Apesar da pretensão de ser uma obra que reúne autores "de diversos países", a esmagadora maioria ou são franceses ou se encontram na França. Por outro lado, existe uma determinada instituição que a patrocina e que imprime um modo muito próprio de abordar as questões da hospitalidade, apesar de construída coletivamente. É isto que frisa o seu organizador, ressaltando "as reuniões de entendimento e diálogo na Maison de La Recherche de 1'Université Blaise-Pascal, já que o empreendimento era dirigido pelo Centre de Recherches sur les Littératures Modernes et Contemporaines (CRLMC)" (p. 36). Nada disso desabona o projeto da publicação, ao contrário, apenas demonstra como é amplo o campo de estudo desenvolvido sobre a hospitalidade, mesmo em se considerando uma determinada perspectiva. Aliás, essa perspectiva deve muito à inspiração de Marcel Mauss e seu "ensaio sobre a dádiva", ressaltado pelo próprio organizador e em vários outros artigos ao longo da obra, sobretudo no seu primeiro bloco dedicado às "definições" de hospitalidade. É essa perspectiva que permite tratar a hospitalidade como "fato social total", na tradição do pensamento sociológico de Mauss.

Dentro dessa perspectiva é que a organização do conjunto dos trabalhos reunidos, em tantas disciplinas de estudo, se encaminhou para um agrupamento em cinco grandes blocos temáticos, ou "partes": 1) "definições"; 2) "civilizações", o qual se subdividiu em "religiões", "culturas", "história"; 3) "lugares, instituições e espaços simbólicos", subdividido segundo essas três temáticas nomeadas; 4) "mitos, figuras e representações", subdividindo-se em "personagens", "figuras da inospitalidade", "arte e literatura"; 5) "filosofia, política e sociedade", se subdividindo em duas partes, "filosofia e política" e "sociedade". As outras partes no final do volume trazem: uma listagem dos autores que colaboraram, com referências sobre sua formação, área de atuação e principais trabalhos realizados; uma que reúne três listas com referências bibliográficas, "geral", "por artigo" e "alguns títulos publicados em português"; a última parte reúne três tipos de índices para orientar o leitor na consulta do volume: "temático", "onomástico" e de "obras citadas". 
O primeiro bloco, "definições", como já mencionado, evidencia bem a qual tradição sociológica e filosófica esse empreendimento se reporta, pois praticamente todos os temas dizem respeito à prática da etnologia, e, sobretudo, à abordagem de Marcel Mauss. É em torno da lógica da "dádiva", que a tensão entre a hospitalidade e a hostilidade frente ao "outro", o "desconhecido", o "estranho", se desenlaça. A análise histórica, lingüística e antropológica dá corpo à compreensão sobre a ambigüidade que cerca a prática da hospitalidade, e as categorias de Mauss ajudam a perceber como ela está no fundamento mesmo de todas as relações humanas. Dessa forma, a própria reflexão sobre a metodologia do trabalho de campo na área da etnologia deve muito a uma melhor compreensão sobre a lógica implícita nas práticas de hospitalidade. Enfim, o bloco termina com um artigo trazendo considerações sobre a prática da hospitalidade na França contemporânea.

No segundo bloco, intitulado "civilizações", pode-se acompanhar uma vasta panorâmica sobre a diversidade da prática da hospitalidade na tradição das grandes religiões, em diferentes áreas culturais espalhadas pelo globo terrestre, e ao longo da história do Ocidente. Um primeiro subbloco temático expõe de maneira relativamente longa a centralidade da hospitalidade na tradição religiosa de origem bíblica e islâmica. $\mathrm{O}$ artigo sobre a "acolhida na Bíblia" demonstra como a hospitalidade está no centro do código da Aliança, implicando no dever da reciprocidade, o que haverá de ter uma influência importante no Novo Testamento, para moldar o princípio da "caridade". Os textos sobre o judaísmo e o islamismo também demonstram a centralidade da hospitalidade, seja por meio de uma benevolência gratuita, seja na forma de um imperativo quanto à partilha dos bens concedidos por Deus. A seguir, ao tratar de áreas culturais tão diversas, em que se incluem a Albânia, os povos da Rússia e do Cáucaso, da Noruega, Romênia e Madagascar, do Extremo Oriente, no caso a China, Japão e Vietnam, ou da Índia, surge de maneira clara a forma pelas quais diferentes leituras sobre a hospitalidade expõem contradições relativas a um mesmo fenômeno, em sua prática e representações culturais. Em todos eles, a hospitalidade surge como uma maneira pela qual o grupo social manifesta o seu modo de administrar a intrusão e ingerência do outro, do estrangeiro, em seu cotidiano. Numa perspectiva não mais das diferentes tradições étnicas e culturais, mas da história ocidental, três textos mostram faces muito diversas sobre o desenvolvimento histórico da hospitalidade no Ocidente. Um primeiro trata das origens da hospitalidade na Grécia antiga, ao estudá-la na epopeia escrita por Homero; a seguir, estuda-se a 
figura do "homo viator", o peregrino na Idade Média, objeto de caridade e generosidade cristã, frente a quem se desdobra todo um cerimonial da hospitalidade; e, por último, o modo muito particular pelo qual se vivia a hospitalidade aristocrática, na Corte de Versalhes, na França do século XVII e XVIII.

O terceiro bloco trata da expressão da hospitalidade no âmbito de diferentes "lugares, instituições e espaços simbólicos", ou o modo pelos quais a hospitalidade organiza o espaço para acolher (ou se defender) do hóspede, ou do outro, desconhecido e estrangeiro. Assim toda a primeira parte se estende em textos que tratam da arquitetura dos prédios e seus espaços, mas também da disposição dos objetos; trata em seguida da forma pela qual a hospitalidade é pensada no espaço da casa, seja ela um castelo, seja ela uma choupana; estuda a hospitalidade em lugares como jardins e montanhas; nas estruturas dos espaços urbanos, no caso das cidades refúgio medievais (incólumes a toda ameaça), ou em lugares surpreendentes como o metrô, "não-lugar" do intenso fluxo urbano, em que milhares de pessoas convivem diariamente. Na segunda parte, os artigos tratam longamente de vários lugares institucionalizados para alguma forma de hospitalidade, sendo, por isso, tão fortemente marcados por regras próprias de co-habitação: os albergues, hospedarias e hotéis; os "hospícios", com suas funções médicas e de "correção moral e social", e que foram tradicionalmente tratados na qualidade de instituições de proteção social de pobres, órfãos, enfermos, inválidos, doentes mentais, moças abandonadas e velhos; as instituições psiquiátricas; os hospitais e sanatórios; contemporaneamente, os centros de alojamento e reinserção social; as casas de misericórdia; além de experiências históricas, exemplificadas por um texto sobre a Ordem do Espírito Santo, ou "hospitalários", e outro sobre a "tragédia da roda" em relação às crianças abandonadas na Europa ocidental, ou ainda outro tratando sobre o desenrolar da hospitalidade cortesã dos salões parisienses no século XVIII e XIX. Os últimos textos fazem uma digressão em relação a "espaços simbólicos": o diário íntimo, a experiência da tradução como acolhida de um texto estrangeiro, a intertextualidade enquanto expressão da relação entre diferentes textos e práticas de leitura, e por fim a acolhida dos mortos, num artigo tratando de cemitérios e rituais funerários.

$\mathrm{O}$ quarto bloco trata do vasto imaginário que foi se criando em torno da hospitalidade, ou da falta dela, ou mesmo de seu contrário, a hostilidade. Nos "mitos, figuras e representações" da hospitalidade, toda a riqueza e diversificação do pensamento ocidental sobre esse tema vem à 
tona. Os personagens míticos, oriundos da Grécia antiga lançam as bases do imaginário da hospitalidade, com figuras como o Anfitrião, Filêmon e Baucis. Outros mitos foram explorados literariamente, por exemplo, na figura de santos, exemplificados em Marta, os Reis Magos, Santo Aleixo, São Julião; outros de caráter profano, destacando-se Don Juan, o hóspede abusador da gentileza do hospedeiro; ou o "judeu errante", o paradoxo da hospitalidade, o hóspede inoportuno que não conhece os modos para receber alguém. A segunda parte desse bloco traz vários textos elencando as "figuras do inóspito", ou seja, aqueles que não são recebidos ou a quem se teme receber. São figuras tipificadas da inospitalidade: o desconhecido ou não familiar, que foge a qualquer classificação; o fantasma ou a assombração que irrompe no mundo dos vivos; o judeu novo rico do século XIX, considerado um parasita social, usurpador e aproveitador, o "bode expiatório" forjado socialmente e que daria origem à onda política do antissemitismo; o vampirismo, ou a intrusão, o "sanguessuga" que se aproveita do corpo que lhe hospeda; o parasitismo; o fantástico, ou a figuração imaginária do inóspito e do impensado incontrolável. Por fim, na parte seguinte, sobre "arte e literatura", vários artigos tratam de artistas representativos, mas não os únicos, de formas originais de se pensar a hospitalidade. O primeiro é Veronese, cuja pintura abriga várias e insólitas imagens da hospitalidade. A seguir vários escritores são tratados, desde o historiador Tito Lívio, que trata da prática da hospitalidade na "res publica" da Roma antiga, até a poesia de Edmon Jabès, que faz o elogio do nomadismo, enquanto reflexão sobre a hospitalidade. A lista contém outros escritores: Christian Hirschfeld, Charles Dickens, Balzac, Marcel Proust, Thomas Mann, Ismail Kadaré, Klossowski, além de um texto tratando de autores da literatura nórdica. Em todos eles fica expressa a riqueza inesgotável do imaginário sobre a hospitalidade para todas as artes.

O quinto bloco debruça-se sobre temas de "filosofia, política e sociedade". Aqui, fica mais uma vez expressa a grande influência que esta obra recebeu da filosofia francesa. Se Marcel Mauss desde o início representa a grande referência, em vários outros textos se reporta intensamente ao pensamento de Jacques Derrida. No primeiro artigo deste bloco, dedicado a ele, se ressalta a sua radicalidade, ao colocar a dimensão ética da hospitalidade, sendo considerado um princípio absoluto e incondicional. Para Derrida, "ética é hospitalidade" (p. 1002), que concomitantemente se realiza e se nega no seu condicionamento a regulamentos, leis, costumes, rituais. Assim, a hospitalidade possui uma 
relação contraditória com as normativas éticas e com todas as formas de direito. A riqueza desse pensamento político sobre a hospitalidade emerge também nos outros textos que se seguem, ao tratar a "acolhida" na forma de um problema para se pensar o direito à Polis, ou o direito à "cidadania" como hospitalidade, expondo um conflito intrínseco ao direito e às leis não escritas. Em torno de conceituações sobre o "exílio", a "migração" e a "exclusão", outros textos tratam do desenvolvimento desses conceitos desde a antiguidade até a forma pelas quais foram problematizadas contemporaneamente na França e na Comunidade Europeia. Outros textos políticos e filosóficos tratam da experiência da franco-maçonaria e do transcendentalismo norte-americano, das contradições entre o ideal humanista da hospitalidade e as ambiguidades do discurso dos direitos humanos. E se a parte filosófica começou com um texto dedicado ao pensamento de Derrida, outro termina essa seção tratando daquele que é considerado sua principal influência, Emmanuel Lévinas: o rosto e a epifania do outro, ou das relações entre ética e hospitalidade. Esse bloco se encerra com estudos sobre alguns fenômenos de sociedade em que está implícita a prática da acolhida e da hospitalidade, por exemplo, nos rituais de vida pública que assumem a forma de espetáculos performáticos, e os banquetes públicos em que se expressam rituais encenando a civilidade, criando pontes entre o ambiente privado e o universo público. Outros artigos tratam de vários fenômenos da vida cotidiana que têm esse sentido: a comensalidade, os animais, o comércio, a amizade, o diálogo, a caridade, risos e sorrisos, as visitas, o "livro de ouro".

Percebe-se, então, que a riqueza do pensamento sobre a hospitalidade vai muito além da problemática da migração, embora sempre pareça se reportar à questão da alteridade, do estranhamento frente ao estrangeiro, dos contatos interculturais. No entanto, é sempre bom destacar que a atualidade desse tema talvez venha justamente dos problemas que a mobilidade humana vem colocando para o homem contemporâneo. Nesse sentido, mais uma vez, quando os textos tentam se reportar a esse momento contemporâneo com casos concretos, os exemplos oriundos da realidade francesa parecem predominar. É o caso de dois grandes artigos, dos mais longos de todo o volume, que discutem a imigração a partir da realidade da França e da Europa. Mesmo sendo o caso europeu e francês um exemplar extremamente rico, e tendo presente que o autor procura realizar o que seria um "mapa geopolítico da hospitalidade" ao estudar sua forma de expressão nas leis e políticas migratórias da Comunidade Europeia, não há como esgotar esse tema unicamente com essa perspectiva. Em todo o 
volume, o tema da imigração e do estrangeiro surge com maior ou menor ênfase em vários artigos, mas na maioria dos textos geralmente é outro o foco de interesse. Assim, ele surge com destaque no texto sobre Derrida, mas, ao contrário do que se poderia esperar, ele está praticamente ausente no artigo que trata da experiência francesa dos Centros de Alojamento e Reinserção Social. Por fim, há estudos que surpreendem, de maneira especial aquele dedicado ao metrô parisiense, em que o autor, além de tratar de questões ligadas à relação entre uma empresa de transporte público e um ideal institucional de hospitalidade, expõe uma reflexão sobre o que seria uma "trans-hospitalidade" no cotidiano desse transporte urbano, enquanto forma de se praticar o "direito à cidade", "no tempo curto, intensivo, da duração breve do deslocamento" (p. 522).

Por fim, se o peso e a quantidade de folhas impressionam nesse livro, ao tratar de um tema nem sempre em evidência, a hospitalidade, a verdade é que ele está longe de esgotar essa temática. É desde já um instrumento bastante útil, e um referencial importante para aqueles que desejam se introduzir e aprofundar no tema. Porém, para um estudo mais aprofundado sobre as relações sobre a migração e a hospitalidade, e o amplo leque de questões correlatas que poderiam ser levantadas, muito ainda está para ser buscado.

Sidnei Marco Dornelas Assessor da Comissão Especial para a Missão Continental e do Setor Pastoral da Mobilidade Humana-CNBB. 